\title{
Fenugreek (Trigonellafoenum-graecum L.) seeds dietary supplementation regulates liver antioxidant defense systems in aging mice
}

Devesh Tewari ${ }^{1,2}$, Artur Jóźwik ${ }^{2 *}$, Małgorzata Łysek-Gładysińska ${ }^{3}$,Weronika Grzybek², Wioletta Adamus-Białek ${ }^{4}$, Jacek Bicki ${ }^{4}$, Nina Strzałkowska ${ }^{2}$, Agnieszka Kamińska ${ }^{5}$, Olaf K. Horbańczuk ${ }^{6}$, and Atanas G. Atanasov 2,7,8,9*

1 Department of Pharmacognosy, School of Pharmaceutical Sciences, Lovely Professional University, Phagwara, 144411, Punjab, India; dtewari3@gmail.com (D.T.)

2 Institute of Genetics and Animal Biotechnology Polish Academy of Sciences, Magdalenka, Poland, aa.jozwik@ighz.pl (A.J.),w.grzybek@ighz.pl (W.G.), b.pyzel@ighz.pl (B.P.), n.strzalkowska@ighz.pl (N.S.) a.atanasov@ighz.pl (A.G.A.)

3 Division of Medical Biology, Institute of Biology, Jan Kochanowski University, Uniwersytecka 7, 25-406, Kielce, Poland, malgorzata.lysek-gladysinska@ujk.edu.pl (M.Ł.G)

4 Department of Surgical Medicine with the Laboratory of Medical Genetics, Collegium Medicum, Jan Kochanowski University, al. IX Wieków Kielc 19A, 25-317, Kielce Poland, wioletta.adamus-bialek@ujk.edu.pl (W.A.B), jacek.bicki@ujk.edu.pl (J.B.)

5 Cardinal Stefan Wyszynski University in Warsaw, Warsaw, Poland, agnieszka.kaminska73@wp.pl (A.K.)

6 Warsaw University of Life Sciences, Warsaw, Poland; olaf_horbanczuk@sggw.pl (O.K.H.)

7 Institute of Neurobiology, Bulgarian Academy of Sciences, 23 Acad. G. Bonchev str., 1113 Sofia, Bulgaria;

8 Department of Pharmacognosy, University of Vienna, 1090 Vienna, Austria;

9 Ludwig Boltzmann Institute for Digital Health and Patient Safety, Medical University of Vienna, Spitalgasse 23, 1090 Vienna, Austria.

* Correspondence: aa.jozwik@ighz.pl (A.J.), a.atanasov@ighz.pl or a.atanasov.mailbox@gmail.com (A.G.A.); Tel.: +48-22736-70-00

\begin{abstract}
:
Fenugreek seeds are widely used in Asia and other places of the world for their nutritive and medicinal properties. In Asia, Fenugreek seeds are also widely recommended for the geriatric populations. Here, we evaluated for the first time the effect of fenugreek seed feed supplementation on the liver antioxidant defense systems in aging mice. The study was conducted on 12 months aged mice which were given fenugreek seed dietary supplement. We have evaluated the activities of various antioxidant defense enzymes like superoxide dismutase (SOD), glutathione reductase (GR), and glutathione peroxidase (GPx), and estimated the phenolics and free radical scavenging properties in mice liver upon fenugreek supplementation. The estimation of SOD, GPx and GR activities in aged mice liver revealed a significant $(\mathrm{P}<0.01)$ difference among all the liver enzymes. Overall, this study reveals that fenugreek seed dietary supplementation has a positive effect in on the activities of the hepatic antioxidant defense enzymes in the aged mice.
\end{abstract}

Keywords: fenugreek; aging; liver; antioxidants; mice 


\section{Introduction}

Liver is a vital organ of the body which is often attacked by reactive oxygen species (ROS)[1,2]. ROS are produced under naturally occurring physiological conditions and significantly contribute in the development of numerous human ailments. A range of antioxidant systems are implied in defense mechanisms of cells against ROS, which can be produced in excess under conditions of stress, and these antioxidant systems include both non-enzymatic and enzymes antioxidants [3]. It has been reported that diet rich in antioxidants enhances the cellular defence mechanisms, by decreasing ROS levels that are generated through cell metabolism in normal cellular conditions [4, 5]. Nicotinamide adenine dinucleotide phosphate (NADPH) is a potent reducing agent which is required to maintain antioxidants of cells in a reduced state, including glutathione[6].

It is reported that increased levels of apoptosis and oxidative damage are presented in the livers of aged mammals. Mainly sinusoidal endothelial cells and bile duct cells are the apoptotic cells in aged livers, since these cell types are highly sensitive to injury by oxidative stress. Therefore, it was assumed that ageing of the liver is mainly induced by the apoptosis induced by ROS in these cells [7]. Recently, rodent studies revealed that there is an involvement of both extracellular and intracellular factors in the liver mass recovery impairment during aging. Among the intracellular factors, age-dependent decrease of Sirtuin-1 (SIRT1), budding uninhibited by benzimidazole-related 1 (BubR1), and Yes-associated protein (YAP) is related to tissue reconstitution dampening and also to cell cycle genes inhibition following partial hepatectomy. Thus, it is also well known that the capacity of liver regeneration after resection is decreased with aging[8].

Fenugreek, botanically equated with Trigonellafoenum-graecum L., is a leguminous herb of Fabaceae family. The seeds of this plantare widely used in Asia, Mediterranean countries, and Africa, as an ingredient of regular diets [9], and are also utilized as medicine, fragrances, in cosmetics, beverages, and for industrial purposes [10]. Various pharmacological effects are attributed to this plant such as antiviral, antimicrobial, carminative, anticholesterolemic, febrifuge, restorative, laxative, expectoral, galactogogue, uterine tonic, anticarcinogenic, antiinflammatory, antioxidant, hypotensive, etc. $[11,12]$. Fenugreek seeds are used in traditional medicine as an antidiabetic, gastric stimulant and also utilized against anorexia. In recent decades, many health benefits of fenugreek seeds were clinically and preclinically validated [13].

Here, we evaluated the effect of fenugreek seed feed supplementation on the liver antioxidant defense systems in aging mice. To the best of our knowledge, this is the first study which investigated the effect of fenugreek seed dietary supplementation in this context.

\section{Materials and Methods}

\subsection{Chemicals}

Superoxide Dismutase Assay Kit, Item No. 706002 (Cayman Chemical Company; Ann Arbor, Michigan 48108 USA), Glutathione Peroxidase Assay Kit, Item No. 703102 (Cayman Chemical Company; Ann Arbor, Michigan 48108 USA),microplate reader Synergy4 (Biotek; Winooski, Vermont 05404 USA), Glutathione Peroxidase Assay Kit, Item No. 703202 (Cayman Chemical Company; Ann Arbor, Michigan 48108 USA), vitamin C (A92902 Sigma-Aldrich L-Ascorbic acid $99 \%$.

\subsection{Experimental animals}

The study was carried out on twenty-four Swiss 12-months old male mice from the population maintained at the Institute of Genetics and Animal Breeding, the Polish Academy of Sciences in Jastrzębiec. The animals were maintained in standard cages of the farm at temperature $22^{\circ} \mathrm{C}$ under standard conditions with $12 \mathrm{~h}$ of daylight and $12 \mathrm{~h}$ of darkness, with an access to food and water. All 
of the described experiments were approved from the Local Ethical Commission. Throughout the entire experiment, the animals were fed with feed dedicated to breeding mice with a total energy of $3625.85 \mathrm{kcal} / \mathrm{kg}$ (the detailed composition of the feed is listed in Table 1).

Table 1. Chemical composition of the used feed (Altromin Spezialfutter GmbH \& Co.)

\begin{tabular}{ll}
\hline Ingredient & Content (in $\mathbf{~ g} / \mathbf{k g})$ \\
\hline Protein & 174466.28 \\
Fat & 50500.25 \\
Fibre & 29980.77 \\
Ash & 55886.78 \\
Moisture & 59418.92 \\
Vitamin C & 20.000 \\
\hline
\end{tabular}

The animals were divided into 4 groups $(n=6)$ two controls (Control Start, CS and Control End, CE) and experimental (Ex5 and Ex10). Before feeding fenugreek, antioxidant status was determined in the liver of control mice (Control Start). The experimental animals (Ex5 and Ex10) for 4 weeks received a diet additionally whole fenugreek seeds $0.125 \mathrm{~g}$ and $0.250 \mathrm{~g}$ per $2.5 \mathrm{~g}$ of feed, respectively. After 4 weeks, the antioxidant potential in the liver of all was determined, using the same analytical procedures. The further procedure strictly followed instructions of the producer.

\subsection{Estimation of Superoxide dismutase (SOD)}

Perfusion of liver tissue was made in phosphate buffered-saline (PBS), at pH 7.4. $1 \mathrm{~g}$ of liver tissue was homogenized in $5 \mathrm{~mL}$ of a $20 \mathrm{mM}$ 4-(2-hydroxyethyl)-1-piperazineethanesulfonic acid (HEPES) buffer (pH 7.2, 1mM ethylenediaminetetraacetic acid (EDTA), $210 \mathrm{mM}$ mannitol, $70 \mathrm{mM}$ sucrose, per $1 \mathrm{~g}$ of tissue) chilled to $4^{\circ} \mathrm{C}$. After that, obtained homogenates were centrifuged at 2,500× $\mathrm{g}$ for $15 \mathrm{~min}$ at $4^{\circ} \mathrm{C}$. To prevent uncontrolled reaction initiation, in this assay it is crucial to store samples on ice until the analysis will be started. The assay procedure was conducted by using the Superoxide Dismutase Assay Kit, Item No. 706002 (Cayman Chemical Company; Ann Arbor, Michigan 48108 USA). Absorbance was measured in duplicate with the help of a microplate reader Synergy4 (Biotek; Winooski, Vermont 05404 USA). The total activity of superoxide dismutase was expressed in $\mathrm{U} / \mathrm{mL}$.

\subsection{Estimation of Glutathione peroxidase (GPx)}

Perfusion of liver tissue was made in PBS buffer, at $\mathrm{pH}$ 7.4. Homogenization of $1 \mathrm{~g}$ liver tissue sample was executed in $5 \mathrm{~mL}$ of buffer containing $50 \mathrm{mM}$ Tris- $\mathrm{HCl}, 5 \mathrm{mM}$ EDTA, and $1 \mathrm{mM}$ dithiothreitol. Homogenates were centrifuged at $10,000 \times \mathrm{g}$ for $15 \mathrm{~min}$ at $4^{\circ} \mathrm{C}$. Supernatants were placed on ice until the analysis started. The procedure was conducted according to the manufacturer instructions by using the Glutathione Peroxidase Assay Kit, Item No. 703102 (Cayman Chemical Company; Ann Arbor, Michigan 48108 USA). Measurements of reaction kinetics in triplicate were made with the help of a microplate reader Synergy4 (Biotek; Winooski, Vermont 05404 USA). Glutathione peroxidase activity was expressed in $\mathrm{nmol} / \mathrm{min} / \mathrm{mL}$.

\subsection{Estimation of Glutatione reductase (GR)}

Perfusion of liver tissue was made in PBS, at $\mathrm{pH}$ 7.4. $1 \mathrm{~g}$ of liver tissue was homogenized in $5 \mathrm{~mL}$ of could buffer $50 \mathrm{mM}$ potassium phosphate ( $\mathrm{pH} 7.5$ ) with $1 \mathrm{mM}$ EDTA chilled to $4^{\circ} \mathrm{C}$. After that, obtained homogenates were centrifuged at $10000 \times \mathrm{g}$ for $15 \mathrm{~min}$ at $4^{\circ} \mathrm{C}$. The procedure was 
conducted according to the manufacturer instructions by using the Glutathione Peroxidase Assay Kit, Item No. 703202 (Cayman Chemical Company; Ann Arbor, Michigan 48108 USA). Measurements of reaction kinetics in triplicate were made with the help of a microplate reader Synergy4 (Biotek; Winooski, Vermont 05404 USA). Glutathione reductase activity was expressed in $\mathrm{nmol} / \mathrm{min} / \mathrm{mL}$.

\subsection{Vitamin $C$}

The level of vitamin $C$ in liver was determined using a LambdaBio-20 spectrophotometer (Perkin Elmer, Waltham, USA). $0.5 \mathrm{~mL}$ of tissue homogenate, $0.5 \mathrm{~mL}$ of distilled water and $1.0 \mathrm{~mL}$ of $10 \%$ TCA were mixed thoroughly and centrifuged for $20 \mathrm{~min} .1 .0 \mathrm{~mL}$ of the obtained supernatant was combined with $0.2 \mathrm{~mL}$ of 2,4dinitrophenylhydrazine-thiourea-copper sulphate reagent and incubated at $37^{\circ} \mathrm{C}$ for $2 \mathrm{~h}$. Subsequently, $1.5 \mathrm{~mL}$ of $65 \%$ sulphuric acid was added and mixed, sample remained at room temperature for another $30 \mathrm{~min}$. Change in colour of the sample was measured at $520 \mathrm{~nm}$. The solutions of vitamin C standards $(0.5-5 \mathrm{mg}$ of vitamin C A92902 Sigma-Aldrich L-Ascorbic acid 99\%) were treated similarly.

\section{7. $\mathrm{DPPH}$}

Measurements for radical scavenging activity were performed with a routine assay procedure [12] using a synthetic DPPH radical (1,1-diphenyl-2-picrylhydrazyl). Folin-Ciocalteu reagent was used as an oxidizing reagent and all the chemicals were purchased from Sigma-Aldrich ChemieGmbh (Munich, Germany) in the highest available purity.

\subsection{Total phenols}

The determination of the content of total phenols was performed as previously described[15]. The samples were thoroughly mixed, and after 8 minutes, $2 \mathrm{~mL}$ of the saturated sodium carbonate solution was added. The next stage of the analysis involved the incubation test at $40^{\circ} \mathrm{C}$ for 30 minutes (until a stable characteristic blue color was developed). The absorbance was measured at 765 and $735 \mathrm{~nm}$ against a blank sample (experimental material replaced with $0.5 \mathrm{~mL}$ ddH2O). Results were read using a calibration curve plotted based on the absorbance of the gallic acid standard in the range of 0 to $0.5 \mathrm{mg} / \mathrm{mL}$ and expressed in $\mathrm{mg}$ of GAE/g tissue or $\mathrm{mg}$ of GAE/mL serum (GAE - gallic acid equivalent).

\section{Results}

The estimation of SOD, GPx and GR in aged mice liver showed that there was a significant $(\mathrm{P}<0.01)$ difference was observed among all the liver enzymes. The concentration of SOD was found less in the CS $(21.97 \pm 0.32)$ and CE $(21.91 \pm 0.6)$ group as compared to the EX5 $(30.64 \pm 1.04)$ and EX 10 $(35.87 \pm 1.61)$ group. There was no significant variation observed in the amount of SOD in the beginning and the end of the experiment in control group, however, the fenugreek seed supplementation in a dose dependent manner increased the SOD in aged mice liver. This clearly reveals that fenugreek seed dietary supplementation significantly increased the concentration of the SOD in the aged mice liver.

On the other hand, the levels of GPx and GR1 decreased significantly $(\mathrm{P}<0.01)$ with the fenugreek seed dietary supplementation. Similar to that of SOD levels, no significant change was recorded in the CS and CE groups in both GPx and GR1 levels which clearly shows that the levels of GPx and GR1 was almost unchanged after four weeks of the experiment. However, there was a significant decrease in the levels of GPx and GR1 enzyme levels in the aged mice liver which clearly reveals that the fenugreek seeds dietary supplement substantially decreases the GPx and GR1 level in a dose dependent manner. The details of the estimated enzymes are presented in Table 2. 
Table 2. The activity of estimated enzymes SOD, GPx and GR (LSM \pm SD) in mice liver

\begin{tabular}{lccc}
\hline & SOD $(\mathrm{LSM} \pm$ SD) & GPx $(\mathrm{LSM} \pm$ SD) & GR 1(LSM \pm SD) \\
\hline Control start & $21.97 \pm 0.32^{\mathrm{A}}$ & $11.71 \pm 0.39^{\mathrm{A}}$ & $165.55 \pm 4.9^{\mathrm{A}}$ \\
Control end & $21.91 \pm 0.6^{\mathrm{A}}$ & $11.93 \pm 0.29^{\mathrm{A}}$ & $166.81 \pm 3.39 \mathrm{~A}$ \\
EX 5\% & $30.64 \pm 1.04^{\mathrm{B}}$ & $7.15 \pm 0.55^{\mathrm{B}}$ & $96.58 \pm 3.35^{\mathrm{B}}$ \\
EX10\% & $35.87 \pm 1.61^{\text {в }}$ & $4.12 \pm 0.14^{\mathrm{C}}$ & $87.94 \pm 1.54^{\mathrm{B}}$ \\
\hline
\end{tabular}

$\mathrm{A}, \mathrm{B}, \mathrm{C}$ Columns with different letters differed significantly $(\mathrm{P}<0.01)$.

We have also evaluated the free radical scavenging activity, vitamin $\mathrm{C}$ and polyphenolic concentration in mice liver. The analysis showed that although there was a slight increase was recorded in vit $\mathrm{C}$ concentration in the fenugreek dietary supplement treated aged mice still, the difference was not significant. Moreover, there was a significant $(\mathrm{P}<0.05)$ difference was recorded in total polyphenols and DPPH free radical scavenging activity. The EX5\% and EX10\% group clearly showed a higher concentration of polyphenols and thereafter a higher DPPH free radical scavenging effect was found as compared to the control groups. The details are presented in Table 3.

Table 3.The level of estimated antioxidant vitamin C, total polyphenols and DPPH in mice liver

\begin{tabular}{lccc}
\hline & $\begin{array}{c}\text { Vit.C } \\
(\text { LSM } \pm \text { SD) }\end{array}$ & $\begin{array}{c}\text { Total polyphenols } \\
(\text { LSM } \pm \text { SD) }\end{array}$ & $\begin{array}{c}\text { Radical scavenging activity by } \\
\text { DPPH(LSM } \pm \text { SD) }\end{array}$ \\
\hline Control & $1.35 \pm 0.03$ & $1.71 \pm 0.03^{\mathrm{a}}$ & $43.79 \pm 1.27^{\mathrm{a}}$ \\
start & & $1.70 \pm 0.02^{\mathrm{a}}$ & $43,81 \pm 0.39^{\mathrm{a}}$ \\
Control & $1.33 \pm 0.01$ & $1.93 \pm 0.03^{\mathrm{a}, \mathrm{b}}$ & $48,64 \pm 1.07^{\mathrm{a}, \mathrm{b}}$ \\
end & $1.37 \pm 0.03$ & $2.06 \pm 0.08^{\mathrm{b}}$ & $51.84 \pm 1.75^{\mathrm{b}}$ \\
EX 5\% & $1.41 \pm 0.02$ & & \\
EX10\% & & & \\
\hline
\end{tabular}

${ }^{\mathrm{a}, \mathrm{b}}$ Columns with different letters differed significantly $(\mathrm{P}<0.05)$.

\section{Discussion}

The increase in the incidences of liver diseases while aging is well accepted [16,17]. The mechanism of liver ageing is though not well understood still oxidative stress is recognized as a major possible contributor and reports are also available that suggested the induction of MAPK pathways by ROS [18].Ageing affects human liver which is manifested by decreased blood flow and volume along with cellular alterations like higher oxidative stress and mitochondrial dysfunction and many more [19]. Apart from this, the ageing is also key risk factor in numerous specific hepatic diseases including non-alcoholic fatty liver disease (NAFLD) [20]. It is interesting to note that treatment related to liver are more often proposed to elderly population [21].Previous study has reported that Fenugreek extract improved lipid metabolism [22] and a clinical study has shown that antioxidant capacity can be improved by the fenugreek seeds as well [23]. In a study conducted to evaluate the protective effect of fenugreek seeds against ethanol toxicity, Thirunavukkarasu et al. 
found that inhibition of GPx activity by ethanol can cause $\mathrm{H}_{2} \mathrm{O}_{2}$ accumulation along with its decomposition products.[24]

In this study we have observed that fenugreek seed dietary supplementation has a positive effect in the regulation of the hepatic enzymes in the aged mice. Elevated SOD levels by fenugreek seeds supplementation is an evidence that this widely used dietary ingredient might have a potential role in the hepatoprotection in aging mediated by oxidative damage. Enhance total phenolic contents and DPPH free radical scavenging activity clearly suggests that antioxidant defence mechanism is improved by fenugreek seed dietary supplementation.

Author Contributions: Conceptualization, A.J.; methodology, A.J; software, O.K.H.; validation, N.S. and W .G.; data curation, A.K.; writing - original draft preparation, D.T.; supervision A.G.A., writing - review and editing, A.G.A., M.Ł.G., W.A.B and J.B..; funding acquisition, A.J.",

Funding: Artur Jóźwik and Atanas G. Atanasov acknowledge the support by the Polish KNOW (LeadingNational Research Centre) Scientific Consortium "Healthy Animal-Safe Food," decision of Ministry of Science and Higher Education No. 05-1/KNOW2/2015 and the European Union under the European Regional Development Fund (Homing/2017-4/41).

Conflicts of Interest: The authors declare no conflict of interest and the funders had no role in the design of the study; in the collection, analyses, or interpretation of data; in the writing of the manuscript, or in the decision to publish the results.

\section{References}

1. Sanchez-Valle, V.; Chavez-Tapia, N. C.; Uribe, M.; Mendez-Sanchez, N. Role of oxidative stress and molecular changes in liver fibrosis: a review. Curr. Med. Chem.2012, 19, 4850-4860, doi:10.2174/092986712803341520.

2 Śliwa-Jóźwik A., Jóźwik A., Kołątaj A., Influence of exogenous glutathione (GSH), as stressfactor, on the activity of lysosome enzymes in some organs of mice. Arch. Tierz. 2002, 3, 307-314.

3. Caetano, A. C.; da Veiga, L. F.; Capaldi, F. R.; de Alencar, S. M.; Azevedo, R. A.; Bezerra, R. M. N. The antioxidant response of the liver of male Swiss mice raised on a AIN 93 or commercial diet. BMC Physiol.2013, 13, 3, doi:10.1186/1472-6793-13-3.

4. Tauler, P.; Aguilo, A.; Fuentespina, E.; Tur, J. A.; Pons, A. Diet supplementation with vitamin E, vitamin $\mathrm{C}$ and beta-carotene cocktail enhances basal neutrophil antioxidant enzymes in athletes. Pflugers Arch.2002, 443, 791-797, doi:10.1007/s00424-001-0770-0.

5. Lipińska P., Atanasov A.G., Jóźwik A. Research Effects of polyphenol-rich chokeberry pomace feeding on antioxidant enzymes activity and oxidation-related parameters in lamb muscle tissues. J. Berry Res. 2019, 9, 95-108, doi:10.3233/JBR-180333.

6. Nelson, M. E.; Lahiri, S.; Chow, J. D. Y.; Byrne, F. L.; Hargett, S. R.; Breen, D. S.; Olzomer, E. M.; Wu, L. E.; Cooney, G. J.; Turner, N.; James, D. E.; Slack-Davis, J. K.; Lackner, C.; Caldwell, S. H.; Hoehn, K. L. Inhibition of hepatic lipogenesis enhances liver tumorigenesis by increasing antioxidant defence and promoting cell survival. Nat. Commun.2017, 8, 14689, doi:10.1038/ncomms14689.

7. Colantoni, A.; Idilman, R.; de Maria, N.; Duffner, L. A.; Van Thiel, D. H.; Witte, P. L.; Kovacs, E. J. Evidence of oxidative injury during aging of the liver in a mouse model. J. Am. Aging Assoc.2001, 24, 51-57, doi:10.1007/s11357-001-0007-3.

8. Pibiri, M. Liver regeneration in aged mice: new insights. Aging (Albany. NY).2018, 10, 1801-1824, doi:10.18632/aging.101524.

9. Smith, M. Therapeutic applications of fenugreek. Altern. Med. Rev.2003, 8, 20-27. 
10. Djeridane, A.; Yousfi, M.; Nadjemi, B.; Boutassouna, D.; Stocker, P.; Vidal, N. Antioxidant activity of some algerian medicinal plants extracts containing phenolic compounds. Food Chem.2006, 97, 654-660, doi:https://doi.org/10.1016/j.foodchem.2005.04.028.

11. Moradi, N.; Moradi, K. Physiological and pharmaceutical effects of fenugreek (Trigonella foenum-graecum L.) as a multipurpose and valuable medicinal plant. Glob. J. Med. plant Res.2013, 1, 199-206.

12. Man, S. M.; Păucean, A.; Călian, I. D.; Mureșan, V.; Chiș, M. S.; Pop, A.; Mureșan, A. E.; Bota, M.; Muste, S. Influence of Fenugreek Flour (Trigonella foenum-graecum L.) Addition on the Technofunctional Properties of Dark Wheat Flour. J. Food Qual.2019, 2019.

13. Srinivasan, K. Chapter 3.15 - Fenugreek (Trigonella foenum-graecum L.) Seeds Used as Functional Food Supplements to Derive Diverse Health Benefits. In; Nabavi, S. M., Silva, A. S. B. T.-N. and N. N. S., Eds.; Academic Press, 2019; pp. 217-221 ISBN 978-0-12-812491-8.

14. Brand-Williams, W.; Cuvelier, M. E.; Berset, C. Use of a free radical method to evaluate antioxidant activity. LWT - Food Sci. Technol.1995, 28, 25-30, doi:https://doi.org/10.1016/S0023-6438(95)80008-5.

15. Škerget, M.; Kotnik, P.; Hadolin, M.; Hraš, A. R.; Simonič, M.; Knez, Ž. Phenols, proanthocyanidins, flavones and flavonols in some plant materials and their antioxidant activities. Food Chem.2005, 89, 191-198.

16. Junaidi, O.; Di Bisceglie, A. M. Aging liver and hepatitis. Clin. Geriatr. Med.2007, 23, 889-903, viii, doi:10.1016/j.cger.2007.06.006.

17. Grizzi, F.; Di Caro, G.; Laghi, L.; Hermonat, P.; Mazzola, P.; Nguyen, D. D.; Radhi, S.; Figueroa, J. A.; Cobos, E.; Annoni, G.; Chiriva-Internati, M. Mast cells and the liver aging process. Immun. Ageing2013, 10, 9, doi:10.1186/1742-4933-10-9.

18. Son, Y.; Cheong, Y.-K.; Kim, N.-H.; Chung, H.-T.; Kang, D. G.; Pae, H.-O. Mitogen-Activated Protein Kinases and Reactive Oxygen Species: How Can ROS Activate MAPK Pathways? J. Signal Transduct.2011, 2011, 792639, doi:10.1155/2011/792639.

19. Kim, I. H.; Kisseleva, T.; Brenner, D. A. Aging and liver disease. Curr. Opin. Gastroenterol.2015, 31, 184-191, doi:10.1097/MOG.0000000000000176.

20. Pais, R.; Charlotte, F.; Fedchuk, L.; Bedossa, P.; Lebray, P.; Poynard, T.; Ratziu, V. A systematic review of follow-up biopsies reveals disease progression in patients with non-alcoholic fatty liver. $J$. Hepatol.2013, 59, 550-556, doi:10.1016/j.jhep.2013.04.027.

21. Delire, B.; Lebrun, V.; Selvais, C.; Henriet, P.; Bertrand, A.; Horsmans, Y.; Leclercq, I. A. Aging enhances liver fibrotic response in mice through hampering extracellular matrix remodeling. Aging (Albany. NY).2016, 9, 98-113, doi:10.18632/aging.101124.

22. Srichamroen, A.; Field, C. J.; Thomson, A. B. R.; Basu, T. K. The Modifying Effects of Galactomannan from Canadian-Grown Fenugreek (Trigonella foenum-graecum L.) on the Glycemic and Lipidemic Status in Rats. J. Clin. Biochem. Nutr.2008, 43, 167-174, doi:10.3164/jcbn.2008060.

23. Tavakoly, R.; Maracy, M. R.; Karimifar, M.; Entezari, M. H. Does fenugreek (Trigonella foenum-graecum) seed improve inflammation, and oxidative stress in patients with type 2 diabetes mellitus? A parallel group randomized clinical trial. Eur. J. Integr. Med.2018, 18, 13-17.

24. Thirunavukkarasu, V.; Anuradha, C. V; Viswanathan, P. Protective effect of fenugreek (Trigonella foenum graecum) seeds in experimental ethanol toxicity. Phytother. Res.2003, 17, 737-743, doi:10.1002/ptr.1198. 